\title{
Submandibular Gland Carcinoma ex Pleomorphic Adenoma
}

National Cancer Institute

\section{Source}

National Cancer Institute. Submandibular Gland Carcinoma ex Pleomorphic Adenoma.

NCI Thesaurus. Code C5977.

A carcinoma that arises from a pleomorphic adenoma in the submandibular gland.

Patients usually present with a history of a long-standing tumor mass which grew rapidly in the past few months. Patients with non-invasive or minimally invasive carcinoma have an excellent prognosis. In cases where there is invasion of the surrounding tissues, the clinical course is aggressive. 